\title{
Effects of vitamin D receptor gene polymorphisms on low-resistance training using exercise machines: The 'Power Rehabilitation' program
}

\author{
SHIN-ICHIRO MURAKAMI ${ }^{2}$, TAKEMI OTSUKI ${ }^{1}$, MEGUMI MAEDA ${ }^{1}$, YOSHIE MIURA ${ }^{1}$, SEIKO MORII ${ }^{2}$, \\ KENJI KIYOKANE ${ }^{2}$, SHIN-ICHI HAYAKAWA ${ }^{2}$, ATSUSHI MAEDA ${ }^{2}$, TAKAYO IMAKAWA ${ }^{2}$, \\ SHUNPEI HARADA ${ }^{2}$, TORATARO HANDA ${ }^{2}$, YASUMITSU NISHIMURA ${ }^{1}$, SHUKO MURAKAMI ${ }^{1}$, \\ NAOKO KUMAGAI ${ }^{1}$, HIROAKI HAYASHI ${ }^{1}$, YING CHEN ${ }^{1}$, SHIN-ICHIRO SUEMORI ${ }^{3}$, \\ YUMIKO FUKUSHIMA $^{2}$, SEIKOH NISHIDA ${ }^{2}$ and KEISUKE FUKUSHIMA ${ }^{2}$ \\ ${ }^{1}$ Department of Hygiene, Kawasaki Medical School, 577 Matsushima, Kurashiki 701-0192; \\ ${ }^{2}$ Fukushima Rehabilitation Academy, 18089-31 Yorishima, Asakuchi 714-0101; \\ ${ }^{3}$ Department of Hematology, Kawasaki Medical School, Kurashiki 701-0192, Japan
}

Received August 29, 2008; Accepted October 6, 2008

DOI: 10.3892/ijmm_00000104

\begin{abstract}
The enhancement and promotion of health is necessary to maintain the quality of life (QOL) of the aged population in developed nations such as Japan where the number of elderly has been increasing rapidly. For this purpose, low-resistance training using exercise machines ('Power Rehabilitation') has been established as a rehabilitation program. To investigate the individual factors which influence the effects of 'Power Rehabilitation', single nucleotide polymorphisms (SNPs) in the vitamin D receptor (VDR) gene and the ciliary neurotrophic factor (CNTF) gene were analyzed, and the relationship between SNP patterns and the effects of 'Power Rehabilitation' was evaluated. 'Power Rehabilitation' had an effect on the physiological functions involved in the activities of daily life (ADL) rather than muscle strength and size. In addition, certain SNP patterns showed better improvement of parameters associated with the effects of 'Power Rehabilitation' as analyzed by comparison between SNP patterns and factor analysis. Large scale analyses are required to ensure this tendency and to discover individual factors which may help to promote the health and QOL of the aged population.
\end{abstract}

\section{Introduction}

Recently, in developed nations in Europe and North America, there has been a trend towards an increase in the aged

Correspondence to: Dr Takemi Otsuki, Department of Hygiene, Kawasaki Medical School, 577 Matsushima, Kurashiki 701-0192, Japan

E-mail: takemi@med.kawasaki-m.ac.jp

Key words: vitamin D receptor, single nucleotide polymorphism, rehabilitation, low-resistance training population with this age group being dominant $(1,2)$. For example, the population of people older than 65 years has exceeded $20 \%$ of the total population in Japan and is predicted to be $30 \%$ by 2025 , and $40 \%$ by 2055 (3-5). In addition, the decreasing birth rate is also magnifying this trend. This phenomenon has led to nation-wide issues such as the rapid increase in the costs for medical care. Japan implemented an elderly care insurance system to resolve this issue in 2000. Although this system includes several operational problems, elderly people in Japan have reaped the benefits of this system which include a plentitude of senior care housing and the prevalence of rehabilitation institutes.

After one decade, since the start of the elderly care insurance system, the quality of life (QOL) of elderly people has attracted attention since senescence and its associated multiple disorders such as paralysis caused by cerebral vascular diseases and dementia have greatly reduced the hope of a well-fulfilled life for many elderly people. Thus, the development of procedures for the enhancement and promotion of health in aged people are required in the areas of medicine and welfare.

Low-resistance training using exercise machines is one of the procedures of the rehabilitation program developed in Japan $(6,7)$. It is called 'Power Rehabilitation'. As shown in Fig. 1, aged people who possess no or slight impairment of physical activity train using exercise machines. The weight loading for them is very slight and time for loading is 5 to $10 \mathrm{~min}$. Using this program, some aged people improve their QOL and their ratio of impairment for assessment for the elderly care insurance system.

In this study, we investigated the relationship between the effects of 'Power Rehabilitation' and individual factors such as single nucleotide polymorphisms (SNPs) of particular gene(s) since the same program does not yield similar effects in all individuals and it is well known that many SNPs affect sensitivity for various diseases and physiological situations 

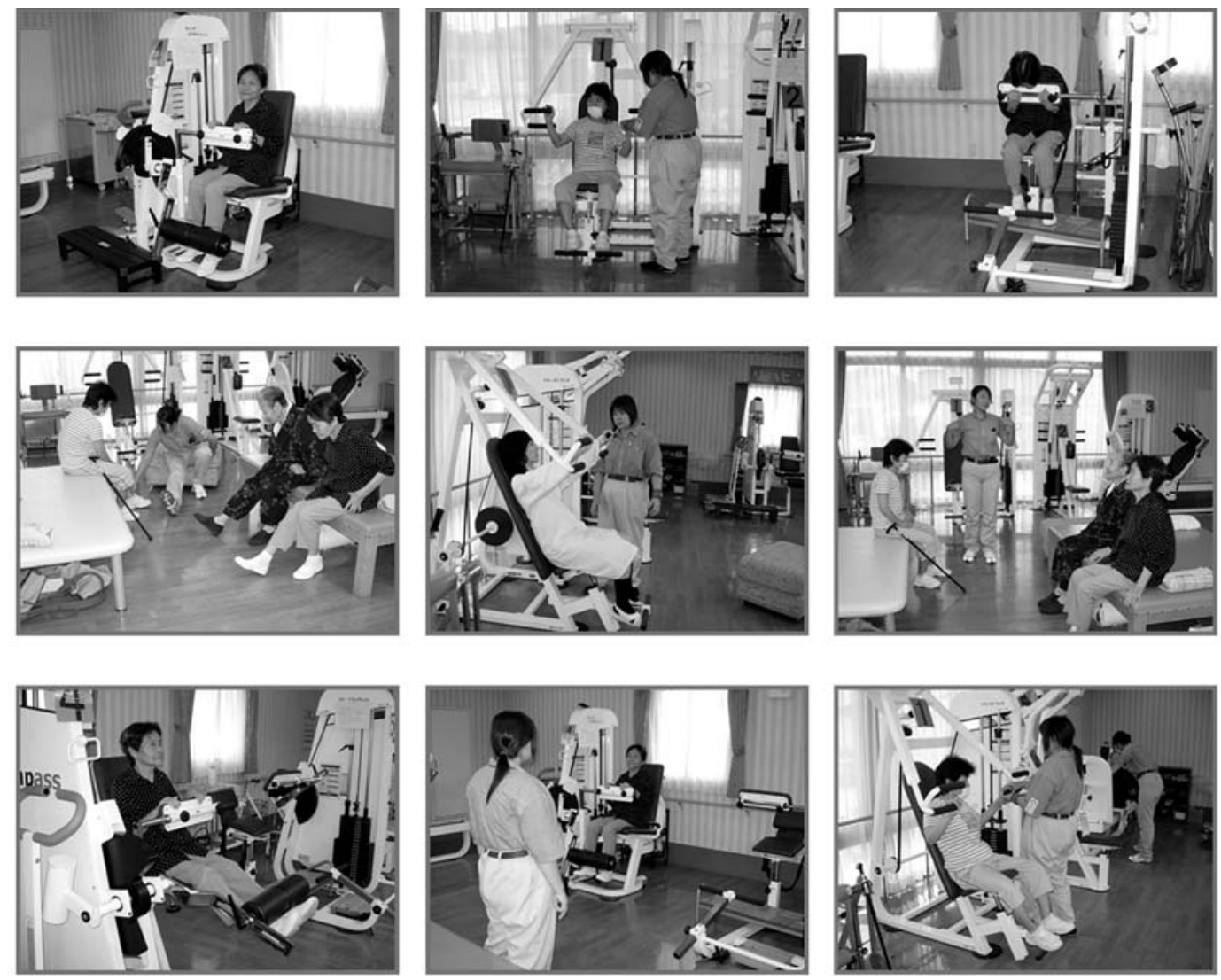

Figure 1. Images of 'Power Rehabilitation'. Aged people are using exercise machines with low-resistant loading.

such as bone metabolism $(8,9)$. The results showed that various SNPs seemed to influence the effects of 'Power Rehabilitation', but we could not make a definitive conclusion due to the number of subjects and the relatively short period of observation. However, further study should proceed to assess individual factors such as SNPs to support health enhancement programs for elderly people and enhance their QOL.

\section{Subjects and methods}

Subjects and chemical and biological parameters. All 63 subjects (male:female 24:39, average age 76.78 \pm 9.65 ) were Japanese and had no to slight health impairments. Maximum impairment was defined as hemi-paralysis. In addition, most people had no or slight dementia, cancers and other progressive diseases. All subjects were enrolled in the 'Power Rehabilitation' program conducted in Iruka-no-Ie ('Dolphin's house') rehabilitation center conducted by Fukushima Rehabilitation Academy, Asakuchi City, Okayama Prefecture, Japan. Specimens were taken from subjects from whom informed consent had been obtained. This study was approved by the ethics committees of Kawasaki Medical School and Fukushima Rehabilitation Academy.

As shown in Fig. 2, before starting 'Power Rehabilitation', all subject parameters were measured. To assess general condition, height, weight, body mass index (BMI) [body weight $(\mathrm{kg}) /$ body height $\left.^{2}(\mathrm{~cm})\right]$, body fat ratio (BFR), hemoglobin A1c (HbA1c), atherosclerosis index (ASI) [(total cholesterol minus HDL-cholesterol)/HDL-cholesterol] were checked. Blood examinations were divided in two parts. For general condition, CBC (complete blood count), cholesterol, triglyceride, high density lipoprotein (HDL)-cholesterol, low density lipoprotein (LDL)-cholesterol, liver and renal function tests were examined. For special features, factors related to the muscle, i.e., patterns of creatine phosphokinase (CPK)-isozyme and lactic dehydrogenase (LDH)-isozyme, serum concentrations of myoglobin, vitamin $\mathrm{D}$, and active vitamin $\mathrm{D}_{3}\left(1 \alpha, 25\right.$-dihydroxyvitamin $\left.\mathrm{D}_{3}\right)(1,25 \mathrm{OHVD})$ were measured.

For genetical assessment, initially, four SNPs of the vitamin D receptor (VDR) gene, i.e., Bsm I (10), Fok I (11), Taq I (12) and Apa I (13), SNP of the ciliary neurotrophic factor (CNTF) gene (C174T in exon 9) (14), the Mnl I SNP in the glucocorticoid receptor (GR) gene (15), and SNP in the promoter region of the interleukin (IL)-6 gene (16) were selected. The SNPs in the CNTF and IL-6 genes did not have convenient restriction enzymes to detect SNPs, so the PCR products were directly sequenced. However, since the last two SNPs were not well documented by PCR and sequencing methods, four VDR and CNTF SNPs were applied for analyses.

Analysis for SNPs. Peripheral blood was collected from the cubital vein using ethylenediaminetetraacetic acid (EDTA) as an anti-coagulant and applied for DNA extraction. Extraction was performed using the DNAQuick II DNA extraction kit (Dainippon Pharmaceutical Co. Ltd., Osaka, Japan). For the 


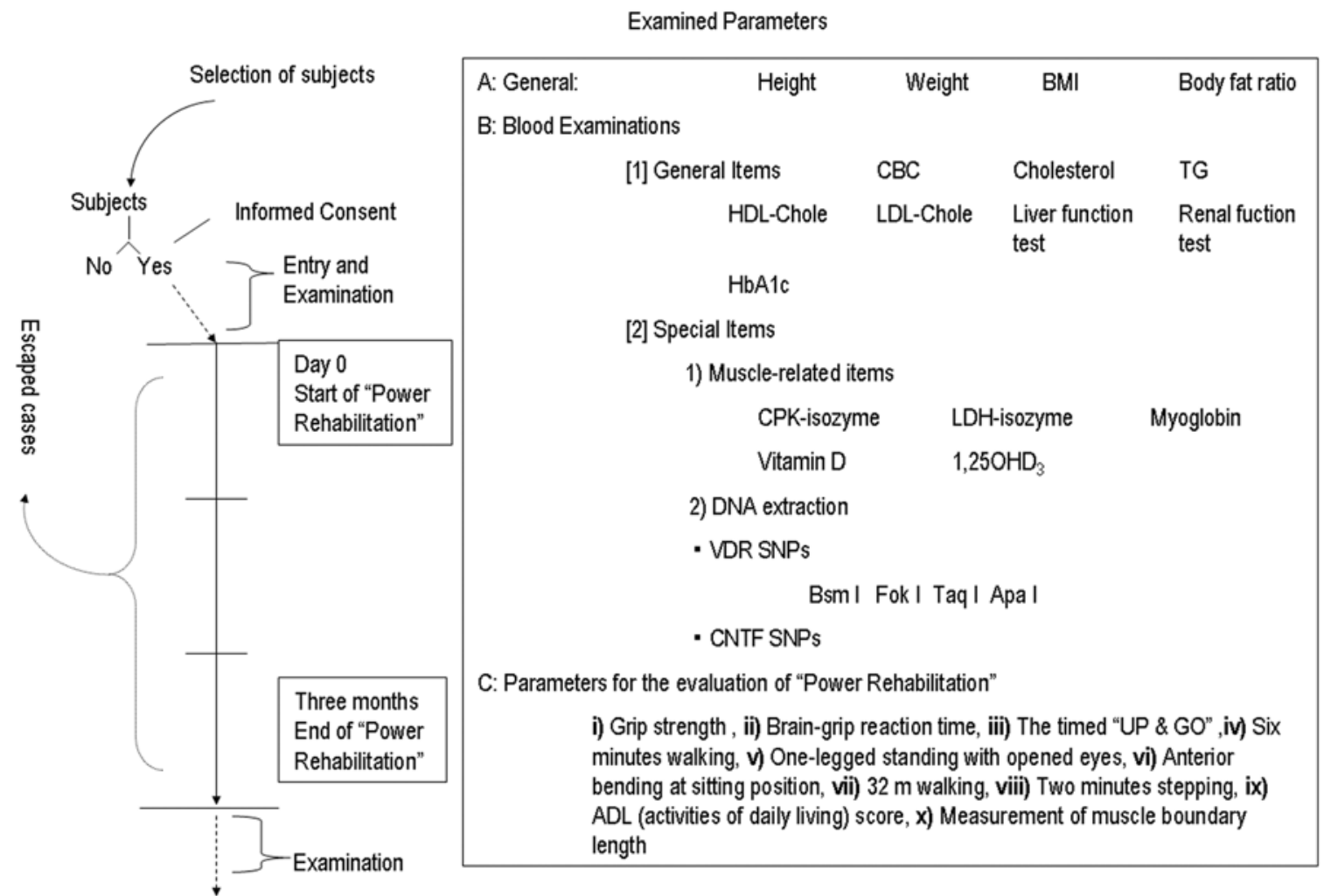

Figure 2. Diagram depicting the steps of this study. BMI, body mass index; CBC, complete blood counts; TG, triglyceride; HDL-chole, high density lipoprotein-cholesterol; LDL-chole, low density lipoprotein-cholesterol; CPK, creatin phosphokinase; LDH, lactic dehydrogenase; $1,25 \mathrm{OHVD}, 1 \alpha, 25-$ dihydroxyvitamin $\mathrm{D}_{3}$; VDR, vitamin D receptor; CNTF, ciliary neurotrophic factor; SNPs, single nucleotide polymorphisms.

Table I. Analyzed SNPs and primer sequences for PCR.

$\begin{array}{ll}\text { VDR Bsm I } & \text { F: 5'-AAGACTACAAGTACCGCGTCAGTGA-3' } \\ & \text { R: 5'-AACCAGCGGGAAGAGGTCAAGGG-3' }\end{array}$

VDR Fok I

F: 5'-AGCTGGCCCTGGCACTGACTCTGCTCT-3'
R: 5'-ATGGAA ACACCTTGCTTCTTCTCCCTC-3'

VDR Apa I and Taq I sites ${ }^{\mathrm{a}}$
Intron 8
F: 5'-CAGAGCATGGACAGGGAGCAAG-3'
Exon 9
R: 5'-GCAACTCCTCATGGCTGAGGTCTCA-3'

$\mathrm{CNTF}^{\mathrm{b}}$
F: CTGCAGACCCCGGTTTCTAT
R: AGTCGCTGGCATTGGAGGGT
Direct sequencing

GR Mnl I

$$
\begin{aligned}
& \text { F: 5'-GATTCGGAGTTAACTAAAAG-3' } \\
& \text { R: 5'-ATCCCAGGTCATTTCCCATC-3' }
\end{aligned}
$$

IL-6 $6^{c}$

\section{F: TGACTTCAGCTTTACTCTTTGT \\ R: CTGATTGGAAACCTTATTAAG \\ FP primer: TGTGCAATGTGACGTCCTTTAGCAT \\ Direct sequencing}

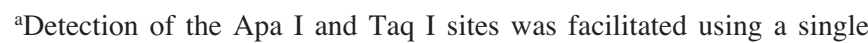
amplification with primers in intron 8 and exon $9 .{ }^{\mathrm{b}} \mathrm{C} 174 \mathrm{~T}$ in exon 9. ${ }^{\mathrm{c}} \mathrm{G} 174 \mathrm{C}$ promoter polymorphism.
}

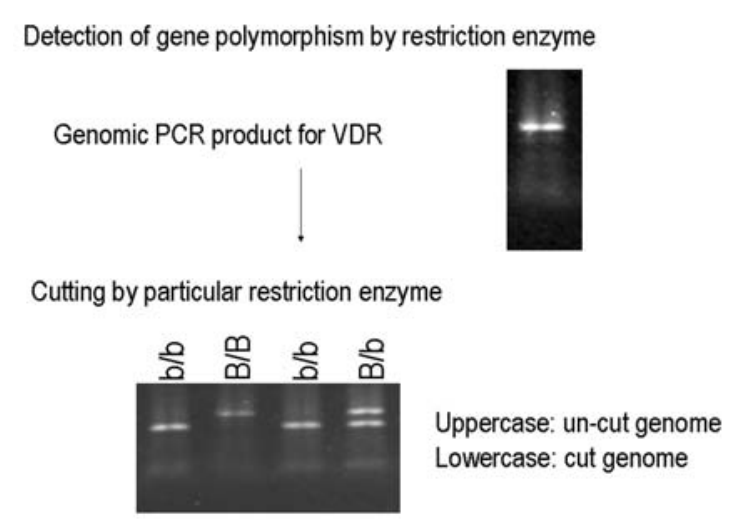

Figure 3. Representative digestion of the PCR product for VDR Bsm I SNP. Genomic DNA from subjects were amplified using the primer set shown in Table I, and PCR products were digested by Bsm I-specific restriction enzyme. Digestion patterns were both alleles digested $(b / b)$, both alleles undigested $(\mathrm{B} / \mathrm{B})$ and product including digested and undigested allele $(\mathrm{B} / \mathrm{b})$.

analysis of the SNPs of the VDR gene, extracted DNA was initially amplified using specific primer sets as shown in Table I and digested by Bsm I, Fok I, Taq I or Apa I. The digested PCR products were electrophoresed and SNPs were assessed as shown in Fig. 3. The large type depicted by an uppercase character of the specific enzyme is the undigested genome and the small type shown by a lowercase letter of specific enzyme is the cut genome. For example, B/B and b/b type were un-cut and cut homozygous genomes, respectively. 
Table II. Analyzed polymorphism patterns.

\begin{tabular}{|c|c|c|c|c|c|}
\hline \multirow[t]{2}{*}{ Gene } & \multirow{2}{*}{$\begin{array}{l}\text { Restriction } \\
\text { enzyme }\end{array}$} & \multicolumn{2}{|c|}{ Pattern } & \multicolumn{2}{|c|}{ Pattern } \\
\hline & & (i) & $\mathrm{n}$ & (ii) & $\mathrm{n}$ \\
\hline \multirow[t]{12}{*}{ VDR } & Bsm I & Large Homo & 4 & Large+ & 16 \\
\hline & & Hetero & 12 & & \\
\hline & & Small Homo & 45 & Small & 45 \\
\hline & Fok I & Large Homo & 35 & Large & 35 \\
\hline & & Hetero & 22 & Small+ & 27 \\
\hline & & Small Homo & 5 & & \\
\hline & Taq I & Large Homo & 44 & & \\
\hline & & Hetero & 17 & & \\
\hline & & Small Homo & 0 & & \\
\hline & Apa I & Large Homo & 7 & Large+ & 40 \\
\hline & & Hetero & 33 & & \\
\hline & & Small Homo & 22 & Small & 20 \\
\hline \multirow[t]{3}{*}{ CNTF } & Sequencing & $\mathrm{C} / \mathrm{C}$ & 32 & $\mathrm{C}$ & 32 \\
\hline & & $\mathrm{C} / \mathrm{T}$ & 16 & $\mathrm{~T}+$ & 32 \\
\hline & & $\mathrm{T} / \mathrm{T}$ & 16 & & \\
\hline
\end{tabular}

Evaluation of the effects of 'Power Rehabilitation'. As shown in Fig. 2, the 'Power Rehabilitation', the low-resistance training using exercise machines, was usually performed twice a week and continued for three months. Before and after the program, ten parameters for evaluation of 'Power Rehabilitation' were measured. The parameters (17-22) were i) grip strength, ii) brain-grip reaction time, iii) the timed 'up \& go', iv) six minutes of walking, v) one-legged standing with opened eyes, vi) anterior bending at sitting position, vii) $32 \mathrm{~m}$ of walking, viii) two minutes of stepping, and ix) ADL (activities of daily living) score, and x) measurement of muscle boundary length. In addition, the Barthel index was evaluated before and after according to previous reports.

Statistical analysis. The parameters for 'Power Rehabilitation' were calculated (post-value minus pre-value). The differences among SNPs in the individual parameters for evaluation of 'Power Rehabilitation' were analyzed by the Mann-Whitney test. In addition, factor analysis $(23,24)$ was carried out. For this, SNPs were numbered from 1 to 3: 1, homozygous (indicated by a capital letter); 2, heterozygous, and 3, homozygous (lowercase letter). All the statistical analyses were performed using StatView software version 5.0 (SAS Institute Inc. Cary, NC, USA) and StatFlex version 5.0 software for Windows (Artech Co. Ltd., Osaka, Japan), which yields results that are compatible with SPSS software.

\section{Results}

SNP patterns. Table II reveals the distribution of four SNPs in the VDR gene and the CNTF SNP. All the patterns and distributions were similar to the reported Asian population patterns. For adequate statistical analyses, the VDR Bsm I SNP was divided into large $(\mathrm{L})+(\mathrm{B} / \mathrm{B}$ and $\mathrm{B} / \mathrm{b})$ and small $(\mathrm{S})$ (b/b) types. VDR Fok I SNP was divided into L (F/F) and S+ (F/f and f/f) types. Similarly, VDR Apa I was divided into L+ and $\mathrm{S}$ types. In addition, CNTF SNP was divided into $\mathrm{C}$ type $(\mathrm{C} / \mathrm{C})$ and $\mathrm{T}+$ type $(\mathrm{C} / \mathrm{T}$ or $\mathrm{T} / \mathrm{T})$.

The effects of 'Power Rehabilitation'. As shown in Table III, the change of each parameter for evaluation of 'Power
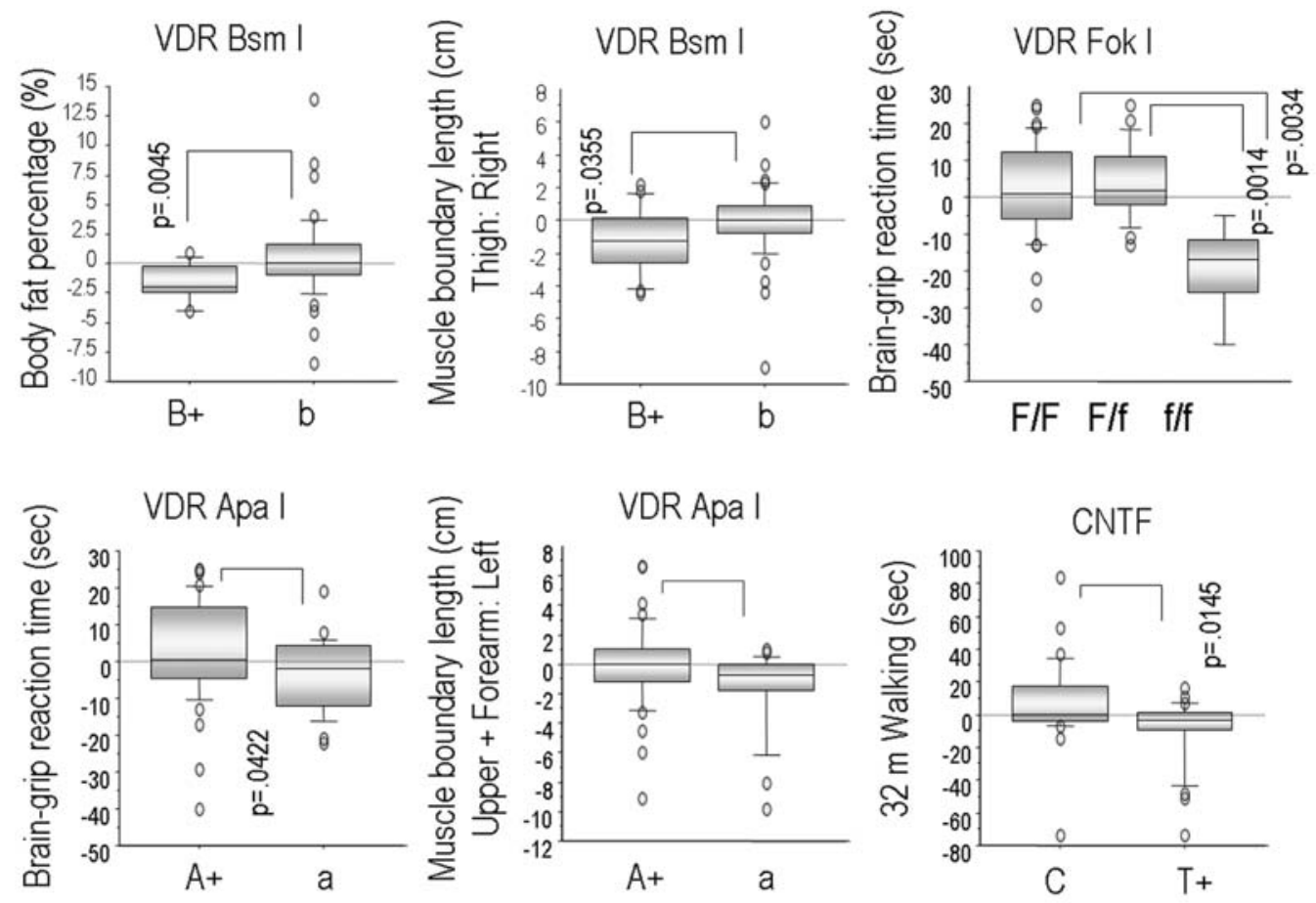

Figure 4. Comparison of SNP patterns and parameters related to the effects of 'Power Rehabilitation'. The statistical analysis was performed using the MannWhitney test. 
Table III. Effects of power rehabilitation. ${ }^{a}$

\begin{tabular}{lrr}
\hline Parameter & Mean & SD \\
\hline BMI & 0.08 & 1.42 \\
BFR $(\%)$ & -0.14 & 3.38
\end{tabular}

Muscle boundary length $(\mathrm{cm})$

Upper arm

$\begin{array}{lcc}\text { Right } & -0.15 & 1.69 \\ \text { Left } & -0.43 & 2.27 \\ \text { Right + Left } & -0.58 & 3.50 \\ \text { Forearm } & & \\ \text { Right } & -0.17 & 1.01 \\ \text { Left } & -0.24 & 1.12 \\ \text { Right + Left } & -0.40 & 1.87 \\ \text { Upper limbs } & & \\ \text { Right } & -0.31 & 1.94 \\ \text { Left } & -0.67 & 2.87 \\ \text { Right }+ \text { Left } & -0.98 & 4.33 \\ \text { Thigh } & & \\ \text { Right } & -0.37 & 2.20 \\ \text { Left } & -0.33 & 2.20 \\ \text { Right }+ \text { Left } & -0.70 & 4.20 \\ \text { Lower thigh } & & \\ \text { Right } & -0.16 & 1.32 \\ \text { Left } & 0.02 & 2.64 \\ \text { Right }+ \text { Left } & -0.14 & 3.18 \\ \text { Lower limbs } & & \\ \text { Right } & -0.53 & 2.93 \\ \text { Left } & -0.31 & 3.78 \\ \text { Right + Left } & -0.84 & 6.08 \\ & & \\ & & \end{array}$

Grip strength

$\begin{array}{lll}\text { Right } & -0.33 & 3.53\end{array}$

$\begin{array}{lll}\text { Left } & 0.37 \quad 3.40\end{array}$

Right + Left $\quad-0.15 \quad 5.98$

One-legged standing with opened eyes ( $\mathrm{min}) \quad 1.92 \quad 26.57$

Anterior bending at sitting position (degree) $\quad 0.34 \quad 5.68$

$\begin{array}{lll}\text { Brain-grip reaction time (min) } & 0.52 & 13.06\end{array}$

$\begin{array}{lll}\text { The timed 'up \&go' (sec) } & -0.08 & 7.78\end{array}$

Six minutes of walking (m) $\quad-0.32 \quad 2.74$

Two minutes of stepping (number of steps) $\quad 8.39 \quad 22.38$

$32 \mathrm{~m}$ of walking (min) $\quad-2.02 \quad 23.85$

Barthel index $\quad 1.64 \quad 5.04$

Cholesterol (mg/dl)

$-8.79 \quad 40.02$

$-9.49 \quad 78.96$

$0.05 \quad 8.47$

$-4.23 \quad 16.79$

$-0.09 \quad 0.47$

$0.04 \quad 0.13$

$-0.09 \quad 0.58$

$-0.25 \quad 4.47$

$-1.90 \quad 26.27$

$-4.77 \quad 17.78$

1 $\alpha, 25$-dihydroxyvitamin $\mathrm{D}_{3}$
Table IV.Parameters showing differences between pre- and post-rehabilitation program.

\begin{tabular}{ccc}
\hline SNP & $\begin{array}{c}\text { Parameter for the } \\
\text { evaluation of 'Power } \\
\text { Rehabilitation' }\end{array}$ & $\begin{array}{c}\text { Better } \\
\text { SNP }\end{array}$ \\
& pattern & \\
\hline
\end{tabular}

VDR

Bsm I

Body fat ratio

$\mathrm{B}+\quad<0.05$

Muscle boundary length

Thigh: right

Thigh: both total

Lower thigh: right + left

Upper and lower thigh: right

Brain-grip reaction time

Triglyceride

b $<0.05$

b $<0.10$

b $<0.10$

b $\quad<0.10$

b $\quad<0.10$

$\mathrm{B}+\quad<0.10$

Apa I

\section{Brain-grip reaction time}

a $\quad<0.05$

Muscle boundary length

Upper and forearms: left

Lower thigh: right

A+ $\quad<0.05$

Upper arm: right

Forearm: left

Forearm: right + left

Walking (6 min)

A+ $<0.05$

$\mathrm{A}+<0.10$

A $+<0.10$

$\mathrm{A}+<0.10$

A $\quad<0.10$

Taq I

\section{BMI}

Triglyceride

Brain-grip reaction time

Muscle boundary length

Thigh: left

Lower thigh: right

Thigh: right + left

Thigh + lower thigh: right

Thigh + lower thigh: right + left

\section{$\mathrm{T} / \mathrm{t}$}

$<0.05$

$\mathrm{T} / \mathrm{t} \quad<0.05$

$\mathrm{T} / \mathrm{T}<0.10$

$\mathrm{T} / \mathrm{T} \quad<0.10$

$\mathrm{T} / \mathrm{T}<0.10$

$\mathrm{T} / \mathrm{T}<0.10$

$\mathrm{T} / \mathrm{T}<0.10$

$\mathrm{T} / \mathrm{T}<0.10$

Fok I

Muscle boundary length

Forearm: right

$\mathrm{f}+\quad<0.05$

Upper + forearm: left

Forearm: right + left

$\mathrm{f}+<0.05$

Grip Strength: left

$\mathrm{f}+\quad<0.10$

F $\quad<0.10$

CNTF

$\begin{array}{lcc}\text { Walking }(32 \mathrm{~m}) & \mathrm{C} & <0.05 \\ \text { Serum vitamin D } & \mathrm{T}+ & <0.10\end{array}$

Rehabilitation' was assessed as post- and pre-values. Regarding muscle boundary lengths, there were no significant changes (all the mean changes were $<1 \mathrm{~cm}$ ), even though most of the lengths decreased. In addition, hand-grip was not remarkably changed. These may indicate that 'Power Rehabilitation' did not significantly affect muscle size and strength.

aThe mean \pm SD for each parameter was calculated using values (after before) 'Power rehabilitation' program. 
Table V. Factor analysis.

\begin{tabular}{|c|c|c|c|}
\hline & Factor 1 & Factor 2 & Factor 3 \\
\hline BMI & 0.21015 & 0.18774 & -0.28996 \\
\hline Body fat percentage & 0.39825 & -0.04937 & -0.08044 \\
\hline \multicolumn{4}{|l|}{ Muscle boundary length } \\
\hline Upper arm: right + left & 0.48813 & 0.36910 & -0.40949 \\
\hline Forearm: right + left & 0.20611 & 0.12956 & -0.48790 \\
\hline Upper + forearm: right + left & 0.50884 & 0.37573 & -0.54413 \\
\hline Thigh: right + left & 0.67405 & 0.36317 & -0.52612 \\
\hline Lower thigh: right + left & 0.41857 & -0.05775 & -0.27589 \\
\hline Thigh + lower thigh: right + left & 0.68748 & 0.20761 & -0.50299 \\
\hline \multicolumn{4}{|c|}{ Parameters for the evaluation of 'Power Rehabilitation' } \\
\hline Grip strength & -0.11204 & 0.08679 & -0.19636 \\
\hline One-legged standing with opened eyes & -0.00688 & 0.11448 & -0.01915 \\
\hline Anterior bending at sitting position & -0.48069 & -0.11757 & -0.13949 \\
\hline Brain-grip reaction time & -0.14576 & 0.32783 & -0.06095 \\
\hline The timed 'up \& go' & 0.09807 & 0.41075 & -0.02763 \\
\hline Walking (6 min) & -0.18940 & -0.02319 & -0.00564 \\
\hline Stepping (2 min) & -0.18085 & -0.01697 & -0.22340 \\
\hline Walking (32 m) & 0.06980 & 0.22596 & -0.01171 \\
\hline \multicolumn{4}{|l|}{ SNPs } \\
\hline VDR Bsm I & 0.57416 & -0.58150 & -0.04314 \\
\hline VDR Fok I & 0.16391 & 0.21901 & -0.00376 \\
\hline VDR Taq I & -0.66532 & 0.49653 & 0.00435 \\
\hline VDR Apa I & 0.22805 & -0.50754 & 0.28492 \\
\hline CNTF & 0.05630 & -0.01311 & -0.23224 \\
\hline \multicolumn{4}{|l|}{ Blood Examinations } \\
\hline Cholesterol & 0.10015 & 0.81685 & -0.07660 \\
\hline Triglyceride & 0.04366 & 0.03077 & -0.78262 \\
\hline HDL-cholesterol & 0.11350 & 0.50874 & 0.64900 \\
\hline LDL-cholesterol & 0.15539 & 0.73875 & 0.09959 \\
\hline Atherosclerosis index & 0.08152 & 0.10073 & -0.80462 \\
\hline $\mathrm{Crn}$ & -0.30804 & 0.24011 & 0.16223 \\
\hline $\mathrm{HbA1c}$ & 0.32982 & 0.45961 & -0.38639 \\
\hline $1,25 \mathrm{OHVD}$ & -0.06200 & 0.01774 & 0.34918 \\
\hline Contribution rate & 11.41405 & 12.12164 & 12.56093 \\
\hline
\end{tabular}

In contrast, most of the functional examinations such as one-legged standing with opened eyes and two-minute stepping were improved except for six-minute walking. These results suggest that 'Power Rehabilitation' is effective for physiological functions, particularly functions for ordinary daily life and may improve QOL of aged people.

In addition, although ASI was not significantly changed, 'Power Rehabilitation' slightly decreased total cholesterol, triglyceride, and LDL-cholesterol levels. Thus, 'Power Rehabilitation' may effectively prevent atherosclerotic progression in the aged population.

Relationship between changes in parameters for evaluation of 'Power Rehabilitation' and SNP patterns. As shown in Fig. 4 and Table IV, certain SNPs showed significant differences regarding parameters for evaluation of 'Power
Rehabilitation'. Since individual muscle boundary lengths were not greatly changed upon completion of the 'Power Rehabilitation' program, most of the SNPs did not affect these. However, VDR Apa I and VDR Bsm I SNPs influenced the muscle boundary lengths in certain muscles. In addition, $\mathrm{F}+$ VDR Fok I SNP, A+ VDR Apa I SNP, and C/C CNTF SNP were associated with a better tendency of functional examinations such as brain-grip reaction time and 32-m walking. Moreover, the B+ VDR Bsm I SNP was better associated with a decrease in body fat ratio.

These results indicate that certain SNPs may influence the effects of 'Power Rehabilitation', although the number of subjects was relatively small in this study.

Factor analysis. Upon assigning the SNP pattern a number as described above, factor analysis $(23,24)$ was performed using 
muscle boundary lengths, functional tests, SNP pattern and general blood examinations. As shown in Table V, VDR Bsm I and Taq I SNPs were related to the muscle boundary lengths revealed as Factor 1. In addition, these two SNPs and VDR Apa I SNP were associated with blood examinations revealed as Factor 2. In contrast, although certain SNPs were related to certain functional tests individually, no factor was consistent with SNPs.

\section{Discussion}

Genetic factors have been implicated in the incidence of various diseases such as cancer $(25,26)$, cardiovascular diseases (27-29) and osteoporosis (8,9). In addition, recent evidence has revealed that certain SNPs may influence the effects of therapeutic drugs and molecular targeting medications for cancers (30-33). The beneficial utilization of individual genomic information may be useful, not only to establish individualized medical diagnosis and therapy, but also to prevent many diseases (25-33). Furthermore, genetic information may be used as a tool for the enhancement and promotion of health and for modifying lifestyle to avoid the occurrence of common disease.

The increase in the aged population in developed nations such as Japan has created a huge problem in a medical and economic context (3-5). The nature of diseases has changed during the last three decades in Japan, and the increases in the costs for medical and welfare services have burdened the national budget, exacerbated by the rapid decrease in the working population in Japan.

It is important to maintain and enhance the health of the aged population. An enhanced QOL of the aged population may reduce medical and welfare budgets. For this purpose, 'Power Rehabilitation' was developed in Japan, not only to prevent cardiovascular diseases and dementia, but also to improve QOL of aged people $(6,7)$. This results in a definite improvement in the rank of the caring score according to the national elderly care insurance system in Japan.

Taken together, it may be important to evaluate how individual factors such as genetic polymorphisms influence the effects of 'Power Rehabilitation'. This study was carried out for this aim.

The results demonstrated that the 'Power Rehabilitation' program improved the physiological functions for activities of daily life (ADL) and enhanced QOL rather than enhancing muscle strength and size. This is reasonable since the resistance for training using exercise machines was low and was designed to maintain muscle strength and size, not to enhance. However, during the three-month 'Power Rehabilitation' program, muscle function and integrative physiological functions improved, therefore achieving the program's aim.

The SNPs analyzed in this study were initially chosen as they were reported to be associated with muscle strength or bone metabolism, since these two organs are considered as two of the most important for enhancing QOL and ADL for the aged population. However, although factor analysis identified various SNPs which tended to the same vector with muscle strength, individual analyses showed no strong relation between SNP patterns and muscle size and strength. Surprisingly, some SNP patterns correlated with the effects of functional tests for ADL. This may encourage the analyses of individual factors including genetic information leading to effective rehabilitation for the aged population.

Our study had a limited number of patients, and all subjects received 'Power Rehabilitation' in a single institute. An enlarged scale of analysis may be required to assess the effects of genetic factors to benefit the 'Power Rehabilitation' program.

\section{Acknowledgements}

The authors thank Ms. Tamayo Hatayama, Minako Katoh, Naomi Miyahara, Shoko Yamamoto, Masae Suzuki, Nobuyo Kasahara and Mizue Kubota for their technical assistance. This study was supported in part by Research Project Grants (nos. 17-6110 and 18-601).

\section{References}

1. Department of State and the Department of Health and Human Services, National Institute on Aging, National Institutes of Health, Washington, DC, USA: Why population aging matters: A global perspective. March 13, 2007, http://www.state.gov/g/ oes/rls/or/81537.htm.

2. WHO: Health topics ageing. http://www.who.int/topics/ageing/ en/.

3. Ministry of Internal Affairs and Communications, Statistics Bureau, Director-General for Policy Planning (Statistical Standards) and Statistical Research and Training Institute, Japan: http://www.stat.go.jp/english/data/handbook/c02 cont.htm.

4. Special report: Japan's Aging population: A challenge for its economy and society, AsiaSource: AsiaToday - A resource of the Asia Society, October 7, 2003, http://www .asiasource.org/ news/at mp 02.cfm?newsid $=102450$.

5. BBC News: Asia-Pacific, fears over Japan's ageing population, December, 22, 2000, http://news.bbc.co.uk/2/hi/asia-pacific/ 1083097.htm.

6. Ohnabe H: Current trends in rehabilitation engineering in Japan. Assist Technol 18: 220-232, 2006.

7. Miyawaki K, Iwami T, Obinata G, Shimada Y, Matsunaga T and Sato M: Development of FES-rowing machine. Conf Proc IEEE Eng Med Biol Soc 2007: 2768-2771, 2007.

8. Hofbauer LC, Brueck CC, Shanahan CM, Schoppet M and Dobnig H: Vascular calcification and osteoporosis - from clinical observation towards molecular understanding. Osteoporos Int 18: 251-259, 2007.

9. Otsuki T, Sakaguchi H, Hatta E, et al: Effects of genetic and nutritional factors on bone mineral density in young adults. Int $\mathrm{J}$ Mol Med 14: 669-676, 2004.

10. Grundberg E, Brändström H, Ribom EL, Ljunggren O, Mallmin H and Kindmark A: Genetic variation in the human vitamin D receptor is associated with muscle strength, fat mass and body weight in Swedish women. Eur J Endocrinol 150: 323-328, 2004.

11. Langdahl BL, Gravholt CH, Brixen K and Eriksen EF: Polymorphisms in the vitamin $\mathrm{D}$ receptor gene and bone mass, bone turnover and osteoporotic fractures. Eur J Clin Invest 30: 608-617, 2000.

12. De Brito Júnior RB, Scarel-Caminaga RM, Trevilatto PC, de Souza AP and Barros SP: Polymorphisms in the vitamin D receptor gene are associated with periodontal disease. J Periodontol 75: 1090-1095, 2004.

13. Naito M, Miyaki K, Naito T, et al: Association between vitamin $\mathrm{D}$ receptor gene haplotypes and chronic periodontitis among Japanese men. Int J Med Sci 4: 216-222, 2007.

14. Arking DE, Fallin DM, Fried LP, et al: Variation in the ciliary neurotrophic factor gene and muscle strength in older Caucasian women. J Am Geriatr Soc 54: 823-826, 2006.

15. Van Rossum EF and Lamberts SW: Polymorphisms in the glucocorticoid receptor gene and their associations with metabolic parameters and body composition. Recent Prog Horm Res 59: 333-357, 2004.

16. Walston J, Arking DE, Fallin D, et al: IL-6 gene variation is not associated with increased serum levels of IL-6, muscle, weakness, or frailty in older women. Exp Gerontol 40: 344-352, 2005. 
17. Wade DT and Collin C: The Barthel ADL index: a standard measure of physical disability? Int Disabil Stud 10: 64-67, 1988.

18. Blum L and Korner-Bitensky N: Usefulness of the Berg balance scale in stroke rehabilitation: a systematic review. Phys Ther 88: 559-566, 2008

19. Sainsbury A, Seebass G, Bansal A and Young JB: Reliability of the Barthel index when used with older people. Age Ageing 34: 228-232, 2005.

20. Mathias S, Nayak US and Isaacs B: Balance in elderly patients: the 'get-up and go' test. Arch Phys Med Rehabil 67: 387-389, 1986.

21. Christofoletti G, Oliani MM, Gobbi S, Stella F, Bucken Gobbi LT and Renato Canineu P: A controlled clinical trial on the effects of motor intervention on balance and cognition in institutionalized elderly patients with dementia. Clin Rehabil 22: 618-626, 2008.

22. Nordin E, Lindelöf N, Rosendahl E, Jensen J and Lundin-Olsson L: Prognostic validity of the timed up-and-go test, a modified getup-and-go test, staff's global judgement and fall history in evaluating fall risk in residential care facilities. Age Ageing 37: 442-448, 2008

23. Otsuki T, Ichihara K, Tomokuni A, et al: Evaluation of cases with silicosis using the parameters related to Fas-mediated apoptosis. Int J Mol Med 4: 407-411, 1999.

24. Wu P, Miura Y, Hyodoh F, et al: Reduced function of $\mathrm{CD} 4^{+} 25^{+}$ regulatory $\mathrm{T}$ cell fraction in silicosis patients. Int J Immunopathol Pharmacol 19: 357-368, 2006.
25. Tomita $\mathrm{N}$ and Oto $\mathrm{M}$ : Molecular genetic diagnosis of familial tumors. Int J Clin Oncol 9: 246-256, 2004.

26. Erichsen HC and Chanock SJ: SNPs in cancer research and treatment. Br J Cancer 90: 747-751, 2004.

27. Nordfors L, Lindholm B and Stenvinkel P: End-stage rena disease - not an equal opportunity disease: the role of genetic polymorphisms. J Intern Med 258: 1-12, 2005.

28. Corella D and Ordovas JM. Single nucleotide polymorphisms that influence lipid metabolism: interaction with dietary factors. Annu Rev Nutr 25: 341-390, 2005.

29. Rao M, Wong C, Kanetsky P, et al: Cytokine gene polymorphism and progression of renal and cardiovascular diseases. Kidney Int 72: 549-556, 2007.

30. Polgar O, Robey RW and Bates SE: ABCG2: structure, function and role in drug response. Expert Opin Drug Metab Toxicol 4: $1-15,2008$.

31. Ueno H, Kiyosawa K and Kaniwa N: Pharmacogenomics of gemcitabine: can genetic studies lead to tailor-made therapy? $\mathrm{Br}$ J Cancer 97: 145-151, 2007.

32. Abraham J, Earl HM, Pharoah PD and Caldas C: Pharmacogenetics of cancer chemotherapy. Biochim Biophys Acta 1766: 168-183, 2006.

33. Cantor CR: The use of genetic SNPs as new diagnostic markers in preventive medicine. Ann NY Acad Sci 1055: 48-57, 2005. 